$(\mathrm{P}<0.05)$ in group I than in group II in all assessment measures (except ulcer free periods and sites). The results of the study are summarized in table $1 \&$ figure 1.

Table 1. A comparison of the individual ulcer characteristics in both groups at baseline and after 24 weeks

\begin{tabular}{|c|c|c|c|c|}
\hline $\begin{array}{l}\text { Ulcer } \\
\text { characteristics }\end{array}$ & $\begin{array}{l}\text { Group I } \\
\text { baseline }\end{array}$ & $\begin{array}{l}\text { Group II } \\
\text { baseline }\end{array}$ & $\begin{array}{l}\text { Group I after } 24 \\
\text { weeks }\end{array}$ & $\begin{array}{l}\text { Group II after } \\
24 \text { weeks }\end{array}$ \\
\hline Number & $13.6 \pm 3.5$ & $12.9 \pm 2.3$ & $8.2 \pm 1.5^{\star \Uparrow}$ & $10.3 \pm 1.7^{\star}$ \\
\hline Size & $11.8 \pm 3.3$ & $12.5 \pm 2.4$ & $7.6 \pm 1.8^{\star \Uparrow 1}$ & $9.6 \pm 1.2^{*}$ \\
\hline Duration & $6.7 \pm 1.1$ & $6.6 \pm 1.7$ & $4.5 \pm 1.9$ * & $5.5 \pm 1.3^{\star}$ \\
\hline Ulcer-free period & $4.7 \pm 0.9$ & $5.1 \pm 1.5$ & $5.7 \pm 1.1^{\star}$ & $5.9 \pm 0.7^{\star}$ \\
\hline Pain & $8.7 \pm 1.2$ & $8.6 \pm 1.4$ & $5.3 \pm 1.5^{\star \Uparrow}$ & $6.7 \pm 1.1^{\star}$ \\
\hline Site & $4.9 \pm 0.8$ & $5.1 \pm 1.2$ & $3.8 \pm 0.6^{*}$ & $4.2 \pm 0.9^{\star}$ \\
\hline
\end{tabular}

*Significant improvement after 24 weeks of the study

"Significant difference between the two studied groups

Conclusion: Combined local therapy (colchicine, steroid, antibiotic and anesthetic) is an effective method in management of oral ulcers in BD.

References:

[1] Taylor J, Glenny AM, Walsh T, et al. Interventions for the management of oral ulcers in Behçet's disease (Review). 2014;(9):CD011018.

[2] Hatemi G, Mahr A, Ishigatsubo $Y$ et al. Trial of Apremilast for Oral Ulcers in Behçet's Syndrome. N Engl J Med. 2019; 381(20):1918-1928.

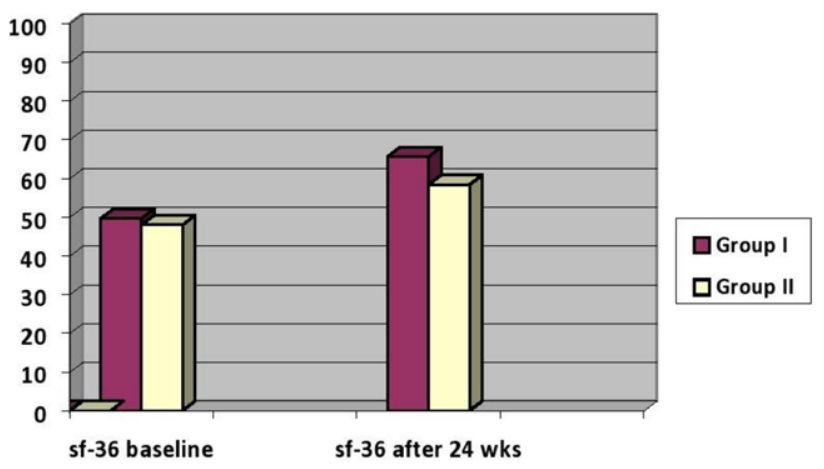

Figure 1: SF-36 (Total score) at baseline and after 24 weeks in both groups

Disclosure of Interests: None declared

DOI: 10.1136/annrheumdis-2020-eular.221

\section{THU0323 MYELOID BIOMARKERS IN GIANT CELL ARTERITIS AND POLYMYALGIA RHEUMATICA - TWO INDEPENDENT COHORTS}

Y. Van Sleen ${ }^{\star 1}$, P. Therkildsen ${ }^{2}$, B. Dalsgaard Nielsen ${ }^{2}$, M. G. Huitema ${ }^{1}$, E. Toonen ${ }^{3}$, A. Boots ${ }^{1}$, P. Heeringa ${ }^{1}$, E. M. Hauge ${ }^{2}$, E. Brouwer ${ }^{1} .{ }^{1}$ University Medical Center Groningen, Groningen, Netherlands; ${ }^{2}$ Aarhus University Hospital, Aarhus, Denmark; ${ }^{3}$ Hycult Biotech, R\&D Department, Uden, Netherlands

Background: Giant cell arteritis (GCA) commonly overlaps with polymyalgia rheumatica (PMR). The incidence of GCA among PMR patients is between 16 and $21 \%$, and both diseases are treated with long-term glucocorticoids (GCs). Patients with GCA suffer from inflammation of their large-sized arteries, whereas PMR is characterized by synovial inflammation. A key question for every physician dealing with a PMR patient is whether or not the patient also has GCA. Symptoms of GCA are often non-specific and difficult to identify. Compared to healthy controls (HCs), newly-diagnosed GCA and PMR patients display a change in leukocyte composition with a shift towards the myeloid lineage, evidenced by elevated monocyte and neutrophil counts. Persistence of this myeloid bias (during and after treatment) is in congruence with mounting evidence that GCs do not sufficiently suppress the vascular/ synovial inflammation, contributing to a relapsing disease course. Yet, it may be difficult to readily identify the myeloid bias in the blood, and therefore easily detectable biomarkers are required to monitor this myeloid bias in GCA and PMR patients.

Objectives: The first objective of this study is to identify disease specific biomarkers for GCA and for PMR using myeloid serum/plasma markers. Next, we assessed whether (a profile of) these markers could be used to reflect the persistent myeloid profile.
Methods: Biomarkers were measured in two independent cohorts: Groningen, the Netherlands (GPS cohort) and Aarhus Denmark (Aarhus cohort). Both cohorts included treatment-naive GCA and PMR patients, supplemented with age- and sex matched HCs (Table 1). Along with the GPS cohort, agematched inflammatory controls were included. GCA-lookalike patients were added in the measurements for the Aarhus cohort. All patients started treatment with GCs, and follow-up samples were measured at 8 weeks for GCA patients. All measurements were performed by ELISA: SCD206, calprotectin, A1AT and elastase in serum samples, whereas PR3 and MPO were measured in plasma samples.

Table 1. Baseline characteristics of the two cohorts

\begin{tabular}{|c|c|c|c|c|c|c|c|c|}
\hline & \multicolumn{4}{|c|}{ GPS cohort } & \multicolumn{4}{|c|}{ Aarhus Cohort } \\
\hline & GCA & PMR & $\mathrm{HC}$ & Infection & $\mathrm{GCA}$ & PMR & $\mathrm{HC}$ & GCA-lookalike \\
\hline $\mathrm{N}$ & 48 & 39 & 50 & 16 & 52 & 25 & 20 & 18 \\
\hline $\begin{array}{l}\text { PET-CT: } \\
\text { positive/ negative/ } \\
\text { not done }\end{array}$ & 32511 & 02910 & NA & NA & 4840 & 0250 & NA & 0135 \\
\hline CRP, median (mg/L) & 52 & 35 & 2 & 70 & 74 & 35 & 1 & 54 \\
\hline
\end{tabular}

Results: Analyses of biomarkers in the two cohorts had mostly equivalen results. Compared to $\mathrm{HCs}$, levels of $\mathrm{SCD} 206$, calprotectin, $\mathrm{PR} 3$ and $\mathrm{A} 1 \mathrm{AT}$ were elevated in GCA, PMR and infection/GCA-lookalike patients. GCA patients had higher levels of SCD206 than PMR patients, but only in the Aarhus cohort this reached statistical significance (Aarhus: $p=0.02$, GPS: $p=0.17$ ). Treatment with GCs substantially affected the biomarker levels: in GCA patients of both cohorts, calprotectin and A1AT levels dropped, SCD206 levels remained high (unchanged), and elastase and PR3 levels increased. Next, we assessed whether the biomarkers correlated with inflammation and the myeloid bias in the GPS cohort. Particularly in GCA patients, A1AT levels correlated with inflammatory marker CRP. Elastase correlated significantly with neutrophil counts in both GCA $(R=0.42)$ and PMR $(R=0.57)$. Calprotectin correlated with neutrophil counts in both GCA and PMR, and with monocyte counts in GCA.

Conclusion: This is one of the first studies in GCA and PMR patients to study biomarkers in two independent cohorts. We consistently showed elevated levels of monocyte/macrophage and neutrophil products in both cohorts. Levels of sCD206 may help in discriminating GCA from PMR patients. The myeloid bias may be monitored using a combination of calprotectin and elastase levels. Additionally, sCD206 or calprotectin may serve as tissue inflammation markers under the cover of GC treatment, a notion to be further investigated using follow-up imaging data.

Disclosure of Interests: Yannick van Sleen: None declared, Philip Therkildsen: None declared, Berit Dalsgaard Nlelsen: None declared, Minke G. Huitema: None declared, Erik Toonen Employee of: Employed by Hycult Biotech, Annemieke Boots Consultant of: Grünenthal Gmbh until 2017, Peter Heeringa: None declared, Ellen-Margrethe Hauge Speakers bureau: Fees for speaking/consulting: MSD, AbbVie, UCB and Sobi; research funding to Aarhus University Hospital: Roche and Novartis (not related to the submitted work)., Elisabeth Brouwer Consultant of: Roche (consultancy fee 2017 and 2018 paid to the UMCG), Speakers bureau: Roche (2017 and 2018 paid to the UMCG)

DOI: 10.1136/annrheumdis-2020-eular.4559

\section{THU0324 CYTOMEGALOVIRUS REACTIVATION AND HIGH INITIAL SERUM CREATININE ARE SIGNIFICANT PROGNOSTIC FACTORS FOR SUBSEQUENT SEVERE INFECTIONS IN PATIENTS WITH ANCA-ASSOCIATED VASCULITIS}

D. Waki ${ }^{1}$, K. Nishimura ${ }^{1}$, T. Yoshida ${ }^{1}$, K. Kadoba ${ }^{1}$, N. Tanaka ${ }^{1}$, H. Murabe ${ }^{1}$, T. Yokota ${ }^{1}{ }^{1}$ Kurashiki Central Hospital, Department of Endocrinology and Rheumatology, Kurashiki, Okayama, Japan

Background: There are several reports that cytomegalovirus (CMV) reactivation resulted in more co-infections affecting survival in rheumatic disease, and CMV reactivation can lead to infections in granulomatosis with polyangiitis patients by inducing CD4+CD28- T cell and depressing naïve $T$ cell populations. ${ }^{1-4}$ Despite this evidence, the prognostic value of CMV reactivation for severe infections in patients with connective tissue disease are still unknown.

Objectives: The aim of this study was to examine prognostic factors for severe infection during the early phase of treatment, especially in CMV reactivation, in patients with antineutrophil cytoplasmic autoantibody (ANCA)-associated vasculitis (AAV) who received initial high dose corticosteroid therapy (prednisolone > $0.8 \mathrm{mg} / \mathrm{kg} / \mathrm{day})$. 